Ciência Florestal, Santa Maria, v. 20, n. 4, p. 589-595, out.-dez., 2010

ISSN 0103-9954

\title{
MOBILIZAÇÃO DE RESERVAS NO EIXO EMBRIONÁRIO E NOS COTILÉDONES DE SEMENTES DE Schizolobium parahyba (Vell.) S. F. Blake DURANTE A GERMINAÇÃO
}

\author{
SEED RESERVE MOBILIZATION IN THE EMBRYONIC AXIS AND COTYLEDONS OF \\ Schizolobium parahyba (Vell.) S. F. Blake DURING GERMINATION
}

Simone Rodrigues de Magalhães ${ }^{1}$ Eduardo Euclydes de Lima e Borges ${ }^{2}$

Ana Paula de Aguiar Berger ${ }^{3}$

\begin{abstract}
RESUMO
O conhecimento da composição química da semente é de extrema importância para auxiliar o entendimento do comportamento durante a germinação, o armazenamento ou mesmo nos processos metabólicos envolvidos na degradação dessas reservas, que, em última instância, afetam o vigor das sementes. Dessa forma, o objetivo deste trabalho foi estudar as alterações no conteúdo de carboidratos, lipídios e proteínas nos cotilédones e no eixo embrionário, durante a germinação de sementes de Schizolobium parahyba (Vell.) S. F. Blake. Para tanto, as sementes foram colocadas para germinar e retiradas amostras periodicamente para as análises. A porcentagem de germinação foi de $88 \%$, iniciando-se no $9^{\circ}$ dia, e a velocidade de germinação foi de 7,7 sementes.dia ${ }^{-1}$. Dentre os ácidos graxos, o ácido oléico predominou tanto nos cotilédones, quanto no eixo embrionário, com variações durante o período de observação. Os demais tiveram pequena variação e não diferiram de forma expressiva. Os teores de amido e de carboidratos solúveis totais comportaram-se de forma similar nos dois compartimentos com decréscimo ao longo do período de embebição. $\mathrm{O}$ teor de proteínas no eixo embrionário, após aumentar em dois dias, decresceu até o 8 dia. Por outro lado, o teor nos cotilédones manteve-se constante nos dois primeiros dias, vindo a cair até o $6^{\circ}$, com aumento no $8^{\circ}$.
\end{abstract}

Palavras-chaves: fisiologia; bioquímica; embebição.

\begin{abstract}
Knowledge of seed chemical composition is very important in order to understand behavior during germination, storage and metabolic processes involved during reserve degradation, the latter of which affects seed vigor. The objective of this study was to assess changes in carbohydrates, lipids and proteins in the embryonic axis and in cotyledons during germination of Schizolobium parahyba. Seeds were placed in Petri dishes to germinate and samples were removed periodically for analyses. Germination was $88 \%$, starting on the ninth day, and the germination rate was 7.7 seeds.day ${ }^{-1}$. Among fatty acids, oleic acids predominated in the embryonic axis and in cotyledons, with changes occurring during the observation period. The others fatty acids showed little change. The levels of starch and soluble carbohydrate behaved in a similar manner in both compartments with a decrease during the imbibition period. Protein levels in the embryonic axis decreased by the eight day, after increasing for two days. On the other hand, protein levels in cotyledons remained constant during the first two days, decreased on the six day and increased on the eight day.
\end{abstract}

Keywords: physiology; biochemistry; imbibition.

1. Graduando em Engenharia Florestal, Universidade Federal de Viçosa, Avenida Peter Henry Rolfs s/n, CEP 36571-000, Viçosa (MG). Bolsista PIBIC/CNPq. simone.magalhaes@ufv.br

2. Engenheiro Florestal, Dr., Professor Adjunto do Departamento de Engenharia Florestal, Universidade Federal de Viçosa, Avenida Peter Henry Rolfs s/n, CEP 36571-000, Viçosa (MG). elborges@ufv.br

3. Bióloga. M.Sc., Professora da Universidade Federal de Viçosa, Avenida Peter Henry Rolfs s/n, CEP 36571-000, Viçosa (MG). anapaula.berger@gmail.com

Recebido para publicação em 21/10/2008 e aceito em 31/05/2010

Ci. Fl., v. 20, n. 4, out.-dez., 2010 


\section{INTRODUÇÃO}

Muitos estudos têm sido realizados com intuito de conhecer a composição química das sementes (BUCKERIDGE et al., 2000; SUDA e GIORGINI, 2000; PONTES et al., 2002; CORTE et al., 2006) uma vez que elas são fundamentais no seu vigor e no desenvolvimento das plantas.

Carboidratos, lipídios e proteínas são as substâncias armazenadas em maiores proporções e possuem teores variáveis nas sementes das diferentes espécies florestais (CORTE et al., 2006). Sementes de Caesalpinia peltophoroides possuem $32 \%$ de carboidratos solúveis, $7,7 \%$ de amido, $50 \%$ de lipídios e 6,8\% de proteínas (CORTE et al., 2006), enquanto sementes de Euphorbia heterophylla contém $3,7 \%$ carboidratos solúveis, $59 \%$ de lipídios, $27 \%$ de proteínas, não sendo detectados teores de amido (SUDA e GIORGINI, 2000).

A presença de açúcares solúveis nos tecidos embrionários influenciou a mobilização dos lipídios em Lupinus luteus durante a germinação (BOREK et al., 2006). A utilização dos açucares solúveis ou do amido ocorre durante a germinação ou no estádio da plântula, dependendo da espécie (PONTES et al., 2002). Em sementes de Euphorbia heterophylla foi verificado que os teores dos açucares solúveis não se alteram durante a germinação (SUDA e GIORGINI, 2000). Por outro lado, em sementes de Caesalpinia peltophoroides as reservas de amido são consumidas durante e após a germinação (CORTE et al., 2006).

Os lipídios são acumulados durante o processo de maturação fisiológica (VALLILO et al., 2007) e hidrolizados no decorrer da germinação para liberação de ácidos graxos, que, por sua vez, são quebrados e liberam energia para a nova planta (HITCHCOCK e NICHOLS, 1971). Em sementes de Apuleia leiocarpa, foi observado que as reservas de lipídios foram mobilizadas durante a germinação, (PONTES et al., 2002), da mesma forma que no endosperma de sementes de Euphorbia heterophylla (SUDA e GIORGINI, 2000). Em sementes de Dalbergia miscolobium, a composição dos ácidos graxos diferiu entre eixo embrionário e cotilédones, especialmente pela presença de altos teores do ácido linolênico no embrião e sua ausência nos cotilédones (SILVA et al., 1998).

Grandes quantidades de proteínas são acumuladas pelas sementes durante a fase inicial da germinação, funcionando como fonte posterior de nitrogênio para a síntese de novas proteínas (BECKERT et al., 2000; LIMA et al., 2008). Em sementes de Dalbergia miscolobium os teores de proteínas aumentaram em 48 horas de embebição, permanecendo assim até a radícula atingir $50 \mathrm{~mm}$ de comprimento (SILVA et al., 1998).

O guapuruvu, como é conhecido popularmente, é uma espécie nativa, que ocorre naturalmente na floresta Atlântica nos estados da Bahia, Espírito Santo, Rio de Janeiro, São Paulo, Paraná, Santa Catarina e Minas Gerais (LORENZI, 1992) e possui enorme potencial econômico com a utilização de sua madeira na produção de móveis, embalagens, dentre outros (JÚNIOR e BELINI, 2002).

Tendo em vista a carência de informação a respeito da mobilização das substâncias de reservas nas sementes de Schizolobium parahyba (Vell.) S. F. Blake durante a germinação, o presente trabalho teve como objetivo avaliar as alterações no conteúdo de carboidratos, lipídios e proteínas nos cotilédones e no eixo embrionário, durante a germinação de suas sementes.

\section{MATERIAL E MÉTODOS}

Foram utilizadas sementes de Schizolobium parahyba coletadas na região de Viçosa, Minas Gerais. Durante o beneficiamento foram eliminados os frutos deteriorados e danificados, sendo acondicionados em sacos plásticos e armazenados em câmara fria a $5^{\circ} \mathrm{C}$, até a realização dos experimentos.

As sementes de guapuruvu tiveram sua dormência superada com a escarificação na extremidade oposta ao eixo embrionário e logo após foram tratadas com fungicida Captan 0,5\%, por três minutos. Em seguida foram semeadas sobre duas folhas de papel do tipo germitest umedecidas com água destilada, em placa de Petri. O teste de germinação foi realizado em germinador à temperatura de $25^{\circ} \mathrm{C}$ constante, sob luz contínua proporcionada por quatro lâmpadas fluorescentes de 40 Watts, sendo utilizadas cinco repetições de vinte sementes cada. Considerou-se germinada a semente que emitiu radícula.

A avaliação da velocidade de germinação foi estimada pelo Índice de Velocidade de Germinação (IVG) de acordo com Santana e Ranal (2004).

A cada 48 horas, por um período de 8 dias, foram retiradas amostras de sementes, suficientes para se obter $1,0 \mathrm{~g}$ de material seco, que foram dissecadas em cotilédones e eixo embrionário, sendo essas amostras secas em estufa a $45^{\circ} \mathrm{C}$, até

Ci. Fl., v. 20, n. 4, out.-dez., 2010 
peso constante. Após moídas, foram acondicionadas em vidros hermeticamente fechados e mantidas congeladas $\left(-20^{\circ} \mathrm{C}\right)$ até a extração e quantificação das reservas.

Para extração dos lipídios as amostras foram colocadas em cartuchos de papel-filtro, pesadas e transferidas para conjunto extrator sohxlet por um período de 24 horas, sendo a extração realizada a frio, com éter de petróleo (SILVA, 1990). Foram realizadas cinco repetições para cada amostra retirada.

Após a extração, o éter de petróleo foi evaporado, sendo o lipídio ressuspendido em hexano e injetadas no cromatógrafo a gás. Os ácidos graxos foram analisados por meio de seus respectivos ésteres metílicos, conforme metodologia descrita por Paula (1995). Foram utilizadas cinco repetições e os resultados expressos em miligramas de ácidos graxos por grama de peso de matéria seca.

Os cromatogramas de ácidos graxos foram obtidos em cromatógrafo a gás Shimadzu CG 14A, equipado com detector de ionização de chama (FID), acoplado ao integrador C-R6A Chromatopac e a um registrador. Foi utilizada a coluna capilar Carbowax $50 \mathrm{~m}$ de $0,22 \mathrm{~mm}$ de sílica fundida, com espessura de $0,25 \mu \mathrm{m}$ (shimadzu). O fluxo do gás de arraste $(\mathrm{H} 2)$ foi de $0,5 \mathrm{~kg} / \mathrm{cm}^{2}$. A temperatura do injetor foi de $220^{\circ} \mathrm{C}$, a do detector de $230^{\circ} \mathrm{C}$ e a da coluna de $190^{\circ} \mathrm{C}$, durante 60 segundos, seguida de uma elevação na razão de $2^{\circ} \mathrm{C} / \mathrm{min}$, até a temperatura final de $230^{\circ} \mathrm{C}$, permanecendo constante por 35 minutos. Foram realizadas três repetições

A extração dos açucares solúveis foi feita conforme metodologia descrita por Black et al. (1996), com modificações. Após cada uma das quatro extrações, a mistura foi centrifugada, retirando-se o sobrenadante, que foi usado na quantificação de carboidratos solúveis totais pelo método colorimétrico (DUBOIS et al., 1956). Cada uma das três repetições foi feita em três replicatas.

Após a extração dos açúcares solúveis, as amostras foram secas em estufa a $45^{\circ} \mathrm{C}$ por 48 horas, e submetidas à digestão com ácido perclórico por 15 minutos para quantificação colorimétrica de amido (PASSOS, 1989). Cada uma das três repetições foi feita em três replicatas.

A extração de proteínas foi realizada conforme Alfenas et al. (1991), que consiste em macerar a amostra em tampão fosfato de sódio, $0,05 \mathrm{M}$ e $\mathrm{pH} 7,0$. A quantificação foi efetuada de acordo com Bradford (1976), utilizando-se curvapadrão construída com albumina sérica bovina
(BSA). Foram realizadas três repetições com três replicadas cada.

$\mathrm{O}$ teste de germinação foi estabelecido no delineamento inteiramente casualizado, sendo os resultados analisados pelo programa Sistema de Análise Estatística (SAEG, versão 8.X, UFV). Como os dados não atenderam as pressuposições da estatística paramétrica, adotou-se à análise descritiva.

\section{RESULTADOS E DISCUSSÃO}

No teste de germinação, foram registrados $88 \%$ de germinabilidade e o IVG foi de 7,7 sementes. dia ${ }^{-1}$, com início da germinação no 9o dia (Figura 1).

Dentre os ácidos graxos, observou-se que o oléico predominou no eixo embrionário e cotilédones (Figuras 2 e 3 ). $\mathrm{O}$ mesmo fato ocorreu, dentre os insaturados, em sementes de Phoenix roebelenii, Phoenix canariensis e Syagrus romanzoffiana (VALLILO et al., 2001). Por outro lado, nos cotilédones e eixo embrionário de sementes quiescentes de Dalbergia miscolobium (SILVA et al., 1998) e em sementes de Medicago sativa (HUANG e GRUNWALD, 1990), o ácido linoléico apresentou maior porcentagem dentre os ácidos graxos analisados.

Os padrões de variação nos teores dos ácidos graxos mirístico, capróico e linoleico foram similares no eixo e nos cotilédones ao longo do período de embebição. De forma oposta, em sementes de Medicago sativa (HUANG e GRUNWALD, 1990), Gossypium hirsutu (PANDEY e SUBRAHMANYAM, 1988) e Tagetes minuta (DREWES e STADEN, 1991), o teor dos ácidos graxos varia de forma aleatória.

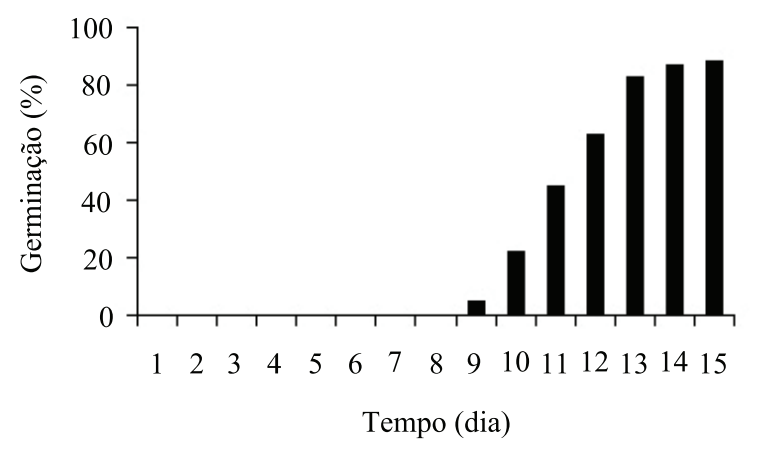

FIGURA 1: Porcentagem de germinação de sementes de Schizolobium parahyba.

FIGURE 1: Germination percentage of Schizolobium parahyba seeds. 


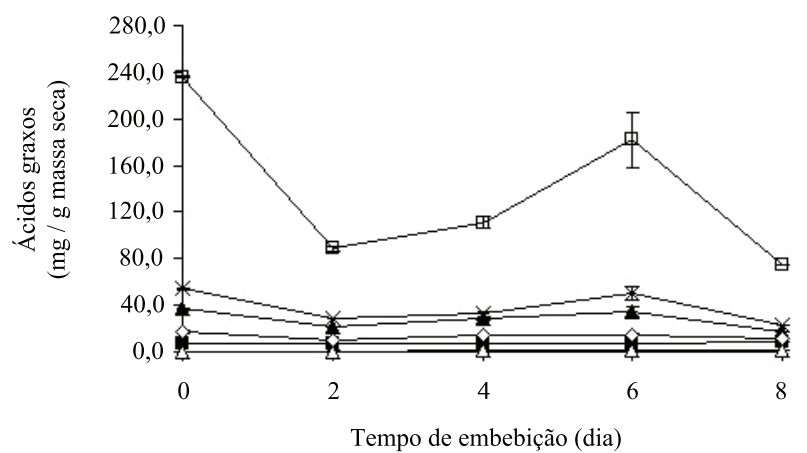

FIGURA 2: Teor médio de ácidos graxos no eixo embrionário de sementes de Schizolobium parahyba. Oléico: $\square$, esteárico: $\mathrm{x}$, palmítico: $\boldsymbol{\Delta}$, linoléico: $\diamond$, capróico: $\boldsymbol{\square}$, mirístico: $\Delta$.

FIGURE 2: Average content of fatty acids in the embryonic axis of Schizolobium parahyba seeds. Oleic: $\square$, stearic: $\mathrm{x}$, palmitic: $\boldsymbol{\Lambda}$, linoleic: $\diamond$, caproic: miristic: $\Delta$.

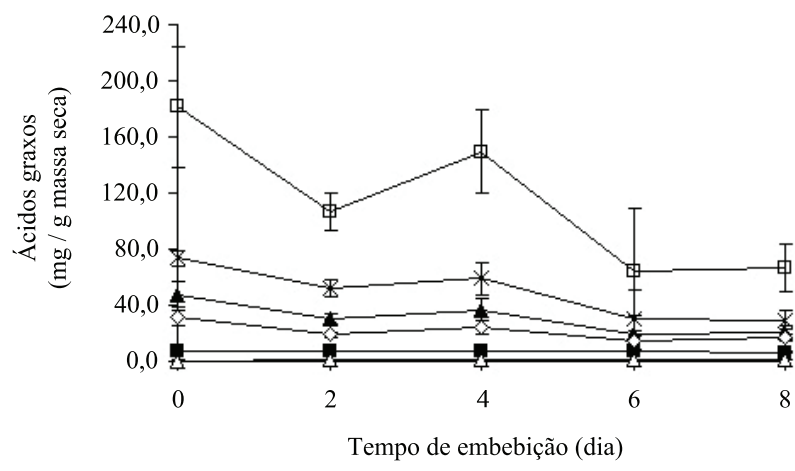

FIGURA 3: Teor de médio de ácidos graxos nos cotilédones de sementes de Schizolobium parahyba. Oléico: $\square$, esteárico: $\mathrm{x}$, palmítico: $\boldsymbol{\Delta}$, linoléico: $\diamond$, capróico: $\boldsymbol{\square}$, mirístico: $\Delta$.

FIGURE 3: Average content of fatty acids in the cotyledons of Schizolobium parahyba seeds. Oleic: $\square$, stearic: $\mathrm{x}$, palmitic: $\boldsymbol{\Delta}$, linoleic: $\diamond$, caproic: $\boldsymbol{\square}$, miristic: $\Delta$.

Os teores de amido no eixo embrionário e cotilédones decresceram até 48 horas, permanecendo estáveis em ambos os compartimentos (Figura 4). $\mathrm{O}$ amido fornece glicose para ser utilizada tanto na respiração, para gerar energia, quanto para compor estruturas físicas durante o crescimento do embrião na fase de germinação. Como a protrusão da radícula somente ocorreu no 9ำ dia, não se supõem que esteja ocorrendo crescimento do embrião, restando a respiração como principal destino da glicose. Resultados semelhantes foram obtidos em sementes de Caesalpinia peltophoroides, em que houve pequeno consumo de amido durante o período germinativo (CORTE et al., 2006), enquanto que em Senna macranthera diminuíram após 72 horas de embebição (BORGES et al., 2002). Ao contrário, Suda e Giorgini, (2000) não detectaram a presença de amido em sementes Euphorbia heterophylla.

Os teores dos carboidratos solúveis totais do eixo e cotilédone apresentaram nítida redução durante a fase inicial da embebição e posterior estabilização nos cotilédones entre o $2^{\circ}$ e $8^{\circ}$ dias (Figura 5). No eixo houve pequeno aumento transitório no sexto dia. A suposta utilização de açúcares na respiração torna-se mais clara, tendo em vista a maior redução nas primeiras horas de embebição. Autores como Borges et al. (2002) e Buckridge \& Dietrich (1996) verificaram o consumo de sacarose e rafinose durante a germinação das espécies Platymiscium pubescens e Sesbania marginata, respectivamente, como as duas primeiras reservas de açúcares solúveis a serem utilizadas, sendo esses oligossacarídeos compostos de glicose, frutose e galactose. A degradação de amido poderia estar suprindo parte dos monossacarídeos que estavam sendo consumidos, justificando o pequeno decréscimo no amido e a manutenção estável dos monossacarídeos observado em ambos os compartimentos durante o período de observação. Assim também Nkang (2002) observou decréscimo no teor dos carboidratos solúveis nos cotilédones de sementes de Guilfoylia monostylis no período inicial da germinação. Contudo, no eixo embrionário de sementes de Euphorbia heterophylla, o conteúdo permaneceu inalterado até 36 horas de embebição (SUDA e GIORGINI, 2000), enquanto em sementes de Caesalpinia peltophoroides, os teores diminuíram continuamente durante a germinação (CORTE et al., 2006).

O teor de proteína no eixo aumentou até 48 horas de embebição seguido de decréscimo contínuo até o $8^{\circ}$ dia. (Figura 6). O teor nos cotilédones, inicialmente mais alto do que o do embrião, manteve-se constante nas primeiras 48 horas, com decréscimo menos acentuado e pequeno aumento no oitavo dia. Do mesmo modo, em Dalbergia miscolobium os teores de proteínas aumentaram no início da embebição (SILVA et al., 1998). No entanto, em Euphorbia heterophylla o conteúdo protéico decresceu constantemente desde o início da embebição (SUDA e GIORGINI, 2000), da mesma forma que em sementes de Caesalpinia peltophoroides (BORGES et al., 2005). De forma 


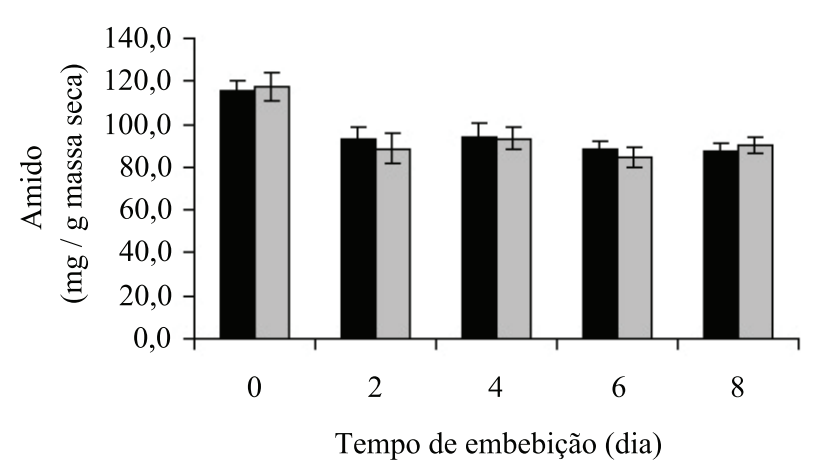

FIGURA 4: Teor médio de amido. Eixo embrionário: $\mathbf{\square}$, cotilédones : $\square$.

FIGURE 4: Average content of starch. Embryonic axis: $\mathbf{n}$, cotyledons: $\square$.

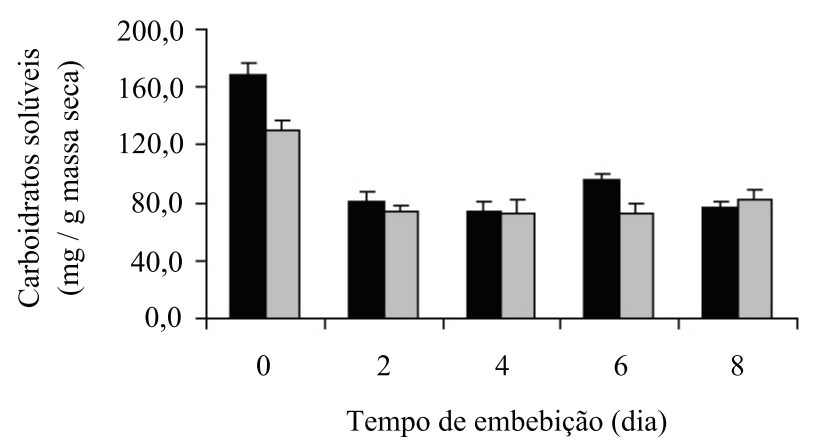

FIGURA 5: Teor médio de carboidratos solúveis totais. Eixo embrionário: cotilédones : $\square$.

FIGURE 5: Average content of soluble carbohydrate. Embryonic axis: cotyledons: $\square$.

oposta, Pontes et al. (2002) registraram aumento significativo no teor de proteína nos cotilédones de Cedrela fissilis, durante a embebição. Por outro lado, em sementes de Qualea grandiflora os teores de proteínas não se alteraram durante a germinação (PAULILO e FELIPPE, 1994).

Percebe-se que não há interação entre as variações nos teores das diferentes reservas, com variações próprias em cada uma delas e em cada compartimento. Os ácidos graxos são os mais rapidamente utilizados, seguidos pelas proteínas, tanto no eixo quanto nos cotilédones, diferentemente dos carboidratos solúveis e do amido que permanecem constantes ao longo das análises. As variações encontradas nos teores de lipídios, no eixo e nos cotilédones, ao longo da germinação não têm correspondências nas demais reservas, indicando uso durante a fase II e, aparentemente, com geração de energia

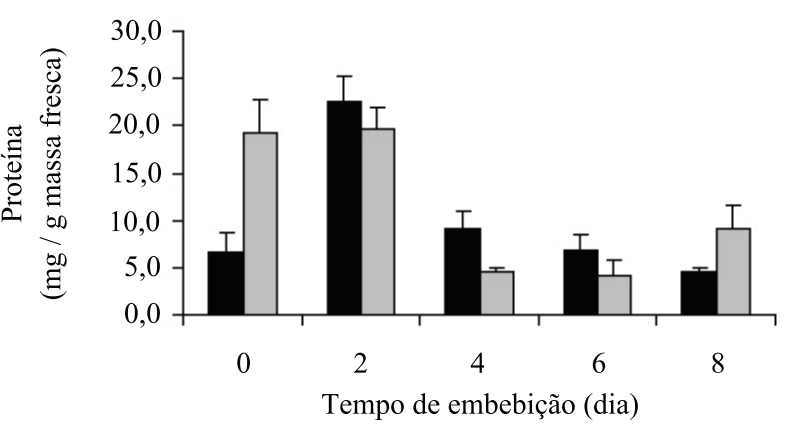

FIGURA 6: Teor médio de proteína. Eixo

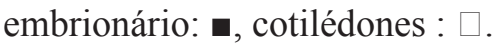

FIGURE 6: Average content of protein. Embryonic axis: $\mathbf{m}$, cotyledons: $\square$.

\section{CONCLUSÃO}

A protrusão da radícula ocorreu a partir do 9-dia de embebição.

Houve mobilização das reservas de carboidrato, lipídios e lipídios durante a germinação.

As proteínas foram utilizadas somente após as demais reservas, com predominância nos cotilédones.

O ácido oléico predominou entre os demais ácidos graxos.

\section{REFERÊNCIAS BIBLIOGRÁFICAS}

ALFENAS, A. C. et al. Eletroforese de proteínas e isoenzimas de fungos e essências florestais. Viçosa: SIF, 1991. $242 \mathrm{p}$.

BECKERT, O. P. et al. Absorção de água e potencial fisiológico em sementes de soja de diferentes tamanhos. Scientia Agrícola, Piracicaba, v. 57, n. 4, p. 671-675, out./dez. 2000.

BLACK, M. et al. Carbohydrate metabolism in the developing and maturing wheat embryo in relation to is desiccation tolerance. Journal Experiment of Botanic, Oxford, v. 47, n. 295, p. 161-169, 1996.

BOREK, S. et al. Ultrastructural and enzymatic research on the role of sucrose in mobilization of storage lipids in germinating yellow lupine seeds. Plant Science, Amsterdan, v. 170, n. 3, p. 441-452, 2006.

BORGES, E. E. L. et al. Crescimento e mobilização de carboidrato em embrião de sementes de fedegoso (Senna macranthera Irwin et Barneby) durante a germinação. Cerne, Lavras, v. 8, n. 1, p.69-76, 2002.

BORGES, E. E. L. et al. Comportamento fisiológico 
de sementes osmocondicionadas de Platymiscium pubescens Micheli (tamboril da mata). Revista Árvore, Viçosa, v. 26, n. 5, p. 603-613, set./out. 2002.

BORGES, E. E. L. et al. Caracterização de alfagalactosidase e sua relação com germinação das sementes de Caesalpinia peltophoroides (Leguminosae Caesalpinioideae). Revista Árvore, Viçosa, v. 29, n. 4, p. 525-533, jul./ ago. 2005.

BRADFORD, M. M. A rapid and sensitive method for the quantification of microgram quantities of proteins utilizing the principle of protein-dye binding. Analytical Biochemistry, New York, v. 72, p. 248-254, 1976.

BUCKERIDGE, M. S.; DIETRICH, S. M. C. Mobilization of the raffinose family oligosaccharides and galactomannan in germinating seeds of Sesbania marginata Benth (LeguminosaeFaboideae). Plant Science, Amsterdan, v. 117, p. 33-43, 1996.

BUCKERIDGE, M. S. et al. Polissacarídeos de reserva de parede celular em sementes, estrutura, metabolismo, funções e aspectos ecológicos. Revista Brasileira de Fisiologia Vegetal, Brasília, v. 12, p. 137-162, 2000.

CORTE, B. V. et al. Mobilização de reservas durante a germinação das sementes e crescimento das plântulas de Caesalpinia peltophoroides Benth. (Leguminosae Caesalpinoideae). Revista Árvore, Viçosa, v. 30, n. 6, p. 941-949, nov./dez. 2006.

DUBOIS, M. et al. Colorimetric method for determination of sugars and related substances. Analytical Chemistry, Washington, v. 28, p. 350$356,1956$.

DREWES, F. E.; STANDEM, J. V. Reserve mobilization during germination of Tagetes minuta L. Annals of Botany, Londres, v. 68, p.79-83, 1991. HITCHOCK, C.; NICHOLS, W. Plant Lipid Biochemistry. London: Academic Press, 1971. 387 p.

HUANG, L; GRUNWALD, C. Lipid and fatty acid changes during germination of alfafa seeds. Phytochemistry, Rockville, v. 29, n. 5, p. 14411445, 1990.

JÚNIOR, G. B.; BELINI, U. L. Produção de lâminas e manufatura de compensados a partir da madeira de guapuruvú (Schizolobium parahyba blake.) proveniente de um plantio misto de espécies nativas. Cerne, Lavras, v. 8, n. 2., p. 1-16, 2002.
LIMA, R. B. S. et al. Primary metabolite mobilization during germination in rosewood (Aniba rosaeodora Ducke) seeds. Revista Árvore, Viçosa, v. 32, n. 1, p. 19-25, jan./fev. 2008.

LORENZI, H. Árvores brasileiras: manual de identificação e cultivo de plantas arbóreas nativas do Brasil. Nova Odessa: Platarum, 1992. 352 p.

NKANG, A. Carbohydrate composition during seed development and germination in two subtropical rainforest tree species (Erythrina caffra and Guilfoylia monostylis). Plant Physiology, Rockville v. 159, n. 5, p. 473-483, 2002.

PANDEY, S. S.; SUBRAHMANYM, V. V. R. Lipid changes in maturing and germination cootonseed. Phytochemistry, Rockville, v. 27, n. 11, p. 34053409, 1988.

PASSOS, L. P. Growth and water status responses of mung bean (Vigna mungo L.) and other dicot species to osmotic stress. 1989. 108f. Tesis (Ph.D.)University of Arizona, Tucson, 1989.

PAULA, V. F. Estudo químico e da interação inseto-planta em Ochroma lagopus Swartz. 1995. 132 f. Dissertação (Mestrado em Agroquímica)-Universidade Federal de Viçosa, Viçosa, 1995.

PAUlilO, M. T. S.; FELIPPE, G. M. Contribuição dos cotilédones e participação de matérias durante o crescimento inicial de Qualea grandiflora Mart. (Vochysiaceae). Revista Brasileira de Botânica, São Paulo, v. 17, n. 2, p. 87-91, 1994.

PONTES, C. A. et al. Mobilização de reservas em sementes de Apuleia leiocarpa (Vogel) J.F. Macbr. (garapa) durante a embebição. Revista Árvore, Viçosa, v. 26, n. 5, p. 593-601, set./out., 2002.

SANTANA, D. G.; RANAM, M. A. Análise da germinação: um enfoque estatístico. 1.ed. Brasília: Ed. Universidade de Brasília, 2004. v.1., 247 p.

SILVA, D. J. Análise de alimentos - métodos químicos e biológicos. Viçosa, UFV, 1990, 165 p.

SILVA, T. R. G. et al. Variação dos componentes armazenados durante a germinação e crescimento da planta de Dalbergia miscolobium. Revista Brasileira de Fisiologia Vegetal, Brasília, v. 10, n. 2, p. 119-124, 1998.

SUDA, C. N. K.; GIORGINI, J. F. Seed reserve composition and mobilization during germination and initial seedling development of Euphorbia heterophylla. Revista Brasileira de Fisiologia Vegetal, Lavras, v. 12, n. 3, p. 226-245, 2000.

VALLILO, M. I. et al. Caracterização química 
e físico-química do óleo das sementes de Platymiscium floribundum Vog. (sacambu), colhidas na fase de desenvolvimento e na época de maturação fisiológica. Revista do Instituto Florestal, São Paulo, v. 19, n. 2, p. 73-80, 2007.
VALILLO, M. I. et al. Composição química e o perfil de ácidos graxos das sementes de quatro espécies de palmeiras cultivadas no estado de São Paulo. Revista do Instituto Florestal, São Paulo, v. 13, n. 2, p. 147-154, dez., 2001. 